\title{
مناهج العلوم الدراسية فى ضوء متطلبات (PISA)
}

\author{
! إعراد \\ الباحث / أحمد مصطفى عوض مصطفى خلف
}

$$
\text { إشراف }
$$

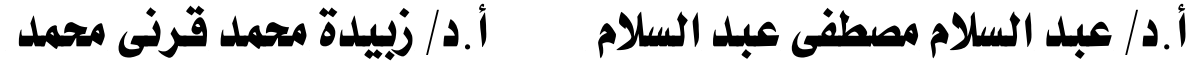

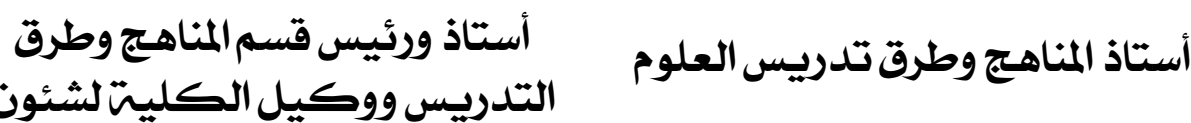
وعميد كليتت التربيت السابق -

المجلت العلميت لكليت رياض الأطفال ـ جامعت المنصورة

$$
\text { المجلد الثانى ـ العدد الرابع }
$$

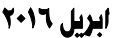




\section{مناهج العلوم الدراسية فى ضوي متطلبات (PISA) المشروع}

الباحث/ أحمد مصطفى عوض مصطفى خلف"

يجب ألا تتصب جهود الإصلاح التربوى - عند تطوير مناهج العلوم -

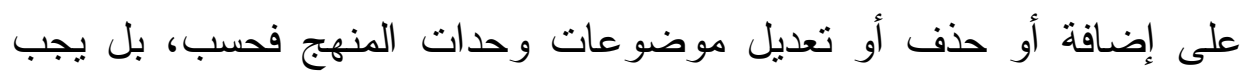
أن يتضمن المنهج موضوعات علمية تساعد فى إعداد جيل من المتعلمين قادرين على بناء وتقام وطنهم فى المستقبل القريب، وفق ما اكتسبوه من

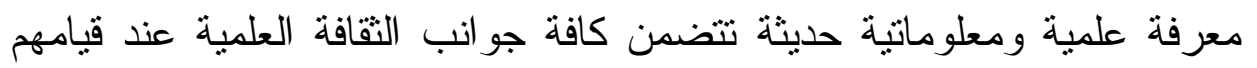
بمعالجة المشكلات و القضايا العلمية وفَقَ إطار من القيم الدينية والأخلاقية

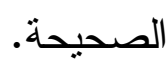

ومن ثم تهاف هذه الورقة إلى تحديد ما يلى: (ماهية المشروع الدولى

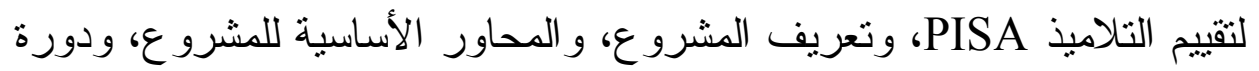

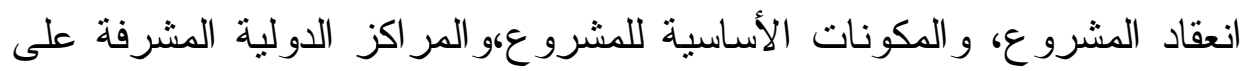

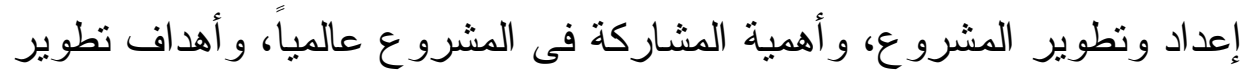

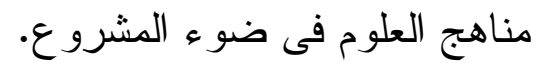

"بحث مستخلص من رسالت دكتوراه للباحث

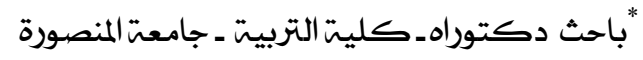


ا - ماهية المشروع الدولى لتقييم التلاميذ PISA:

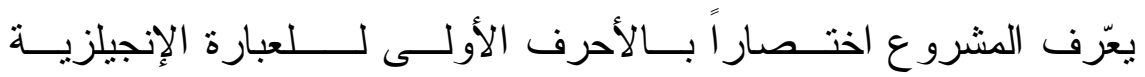

Programme for International Student Assessment عليه منظمة التعاون و التتمية الاقتصادية OECD ومقر ها "باريس"،ويتم إجــر اء

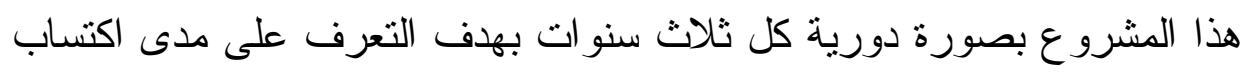

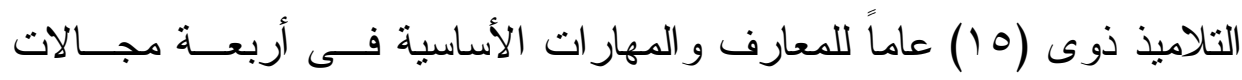

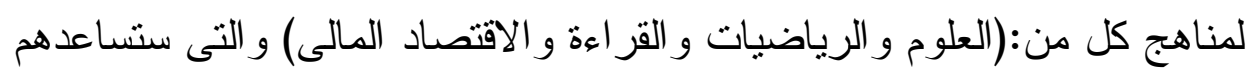

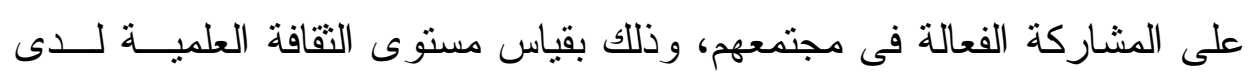

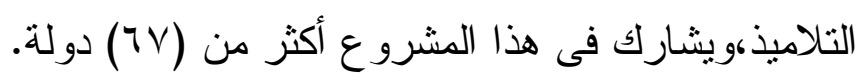

r- تعريف مشروع البرنامج الدولى لتقييم التلاميذ تهتم المؤسسات التربوية بمر اقبة مخرجات تعلّم كل مدرسة بهدف معرفة

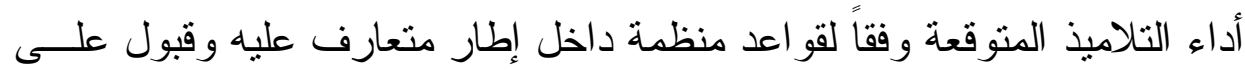

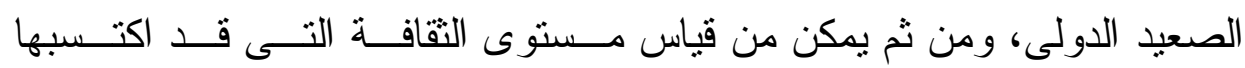

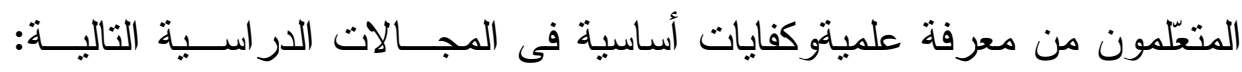

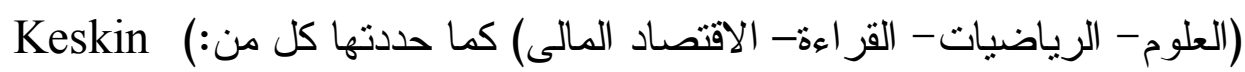
Shelley and ( , 2014, 107)Meeks, et al. (2014, 178) and Ray (Prince), ؛, 2012, 202)Thomson, et al. ؛(, 2013, 84)Yildirium Rutkowski and ؛(Hopstock, et al.), 2011, 18( ؛2012, 3 ؛(Bieber and Martens), 2011, 112 ؛Prusinski), 2011, 2 ؛(Anagoostopoulou, et al., 2010, 50 (Murphy),2010, 29 
؛(Kim, et al.), 2009, 397(ฐThomoson and (Hillman),2010, 10

‘Carmichae, et al.), 2009, 58

r- المحاور الأساسية للمشروع الدولى لتقييم التلاميذ (PISA):

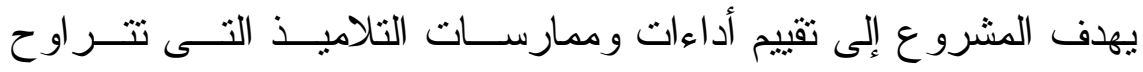

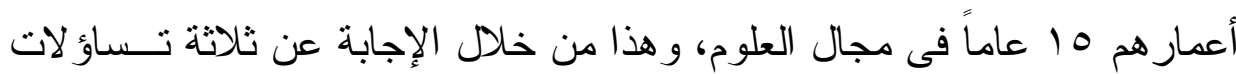

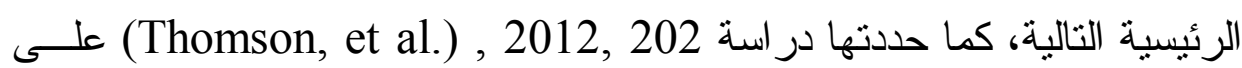
النحو التالى: (الرئلة

1- إلى أى مدى سيكتسب التلاميذ المكونات الأساسية للمعرفة العلمية المتمثلة

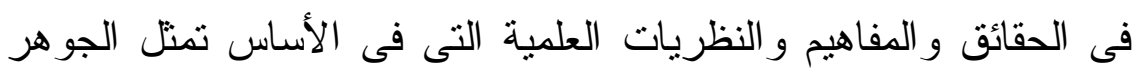

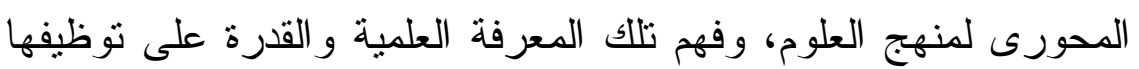

$$
\text { داخل سياقات جديدة أو توليد معرفة أخرى جديدة؟ }
$$

r- إلى أى مدى سيتمكن التلاميذ من تحديد القضايا و المشكلات العلمية التى تتشغل الر أى العام، وتمكنهم من شرح ذلك على علئاً، ونوظيفهم للأدلة العلمية

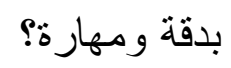

r- إلى أى مدى سيتمكن التلاميذ من تفسير المشكلات و القضايا ذات الصلة

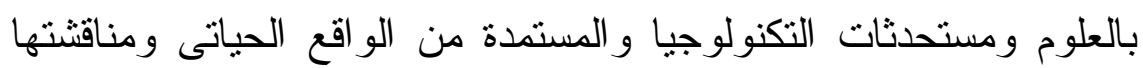
وحلها بالأساليب العلمية المضبوطة ولنئ

ع- دورة انعقاد المشروع:PISA:

يقام الاختبار على المستوى العالمى كل ثلاث سنوات لتلاميذ التى تـصل

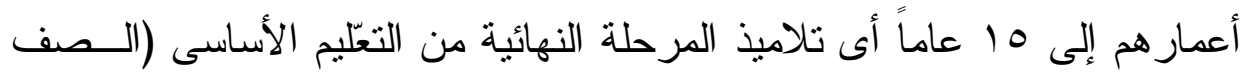


الثالث الإعدادى)، وقد بدأ المشروع من سنة ... بم ويسمح للاول بالمـشاركة

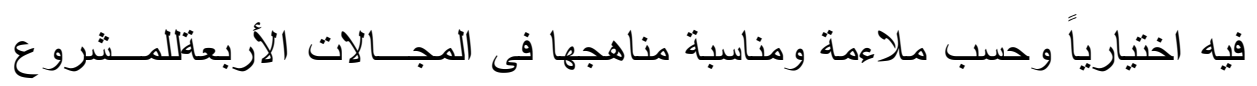
و هى: العلوم و الرياضيات و القز اءة و الاقتصاد المالى. ونئ.

\section{ه شروط تقيم التلاميذ المستهدفين فى مشروع(PISA):}

حدد القائمون على المشروع عدة شروط من الو اجب أن يلتزم بها التلاميذ المستهدفين على النحو التالى:

1- لا يتجاوز عمر المشترك فى اجتياز اختبار المشروع (10) عاماً،ودون الأخذ فى الاعتبار صفوفهم الدر اسية.

r- يستغرق زمن الاختبار ساعتان لكل مجال من المجالات الدر اسية الأربعة

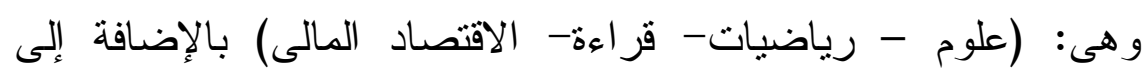
مهار ات حل المشكلات فى كل مجال در اسى.

r- لا يتم إجراء اختبار فى المواد ذات الطابع القومى أو المحلى مثل: التاريخ الإنسانى أو اللغة القومية أو التربية الدينية.

ع - يتم تدريب فئة التلاميذ التى نم اختبار ها مدة زمنية مقدارها شهر ان تحت إثثر اف لجنة متخصصة من منظمة (OECD) ومدربين تابعين للمر اكز المشرفة على إجراء الاختبار داخل كل دولة من الدول التى سنتارك فعلياً.

T- جواتب الثقافة العلمية الأربعة من منظور مشروع (PISA):

قسم المشروع الدولى (PISA 2012) جو انب الثقافة العلمية إلى أربعــة

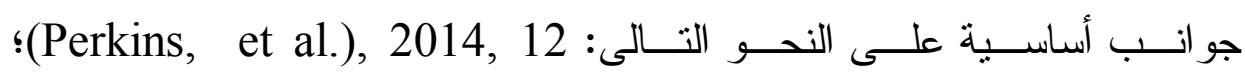


(Thomson, et al.), 2013, 8 ؛(Sothayapetch, et al.), 2013, 83-85

(Gur \& Celik and ؛(Mangez and Hilgers), 2012, 200 ؛ (OECD), 2010c, 27، OECD, 2010d, 20؛Ozoglu), 2012, 2 (Bybee, ؛Bybee, at, al.), 2009 ,866 (OECD) , 2009b , 130 ؛ .(OECD), 2007a, 36-40 ؛(Lan), 2008, 1073-1074 2009, 2 1- جانب المعرفة العلمية Knowledge : وتتمنل فى فهم طبيعة العالم وفقاً إلى مكونات المعرفة من خلال المعرفة عن العلوم، والمعرفة حول

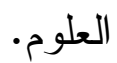

r- جانب الكفايات الأساسية Competencies: وتتمنل فى تتخيص المو اقف العلمية، وتقديم التفسير ات العلمية، و استخدام الأدلة العلمية الدقبولة. r- جانب الاتجاهات العلمية Attitudes : وتتمتل فى الاهتمام بدراسة العلوم، و الدافعية نحو تحمل المسئولية نحو البيئة ومصادرها الطبيبعة،

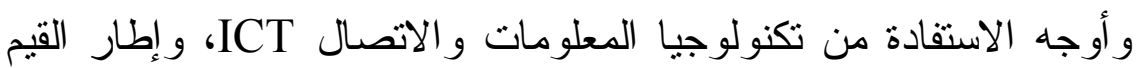

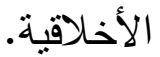

ع - جانب السياقات Context: وتتمتل فى تتوع المو اقف و السياقات التعليمية المستمدة من الحياة الو اقعية سو اء أكانت سياقات شخصية أو اجتماعية أو أو الو عالمية. - مان.

وفيما شكل (1) يوضح العلاقة بين الجوانب الأربعة للثقافة العلمية كما

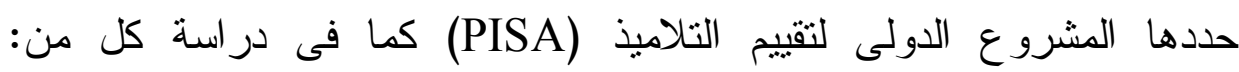
؟Thomson, et al)., 2013, 8 ؛(Thomson, et) al., 2014, 127 ؛(Bybee), 2010, 21 (OECD), 2013, 102؛(OECD), 2013, 102 
على النحو:Bybee, et al.), 2009, 867( (Bradshaw, et) al., 2009, 3

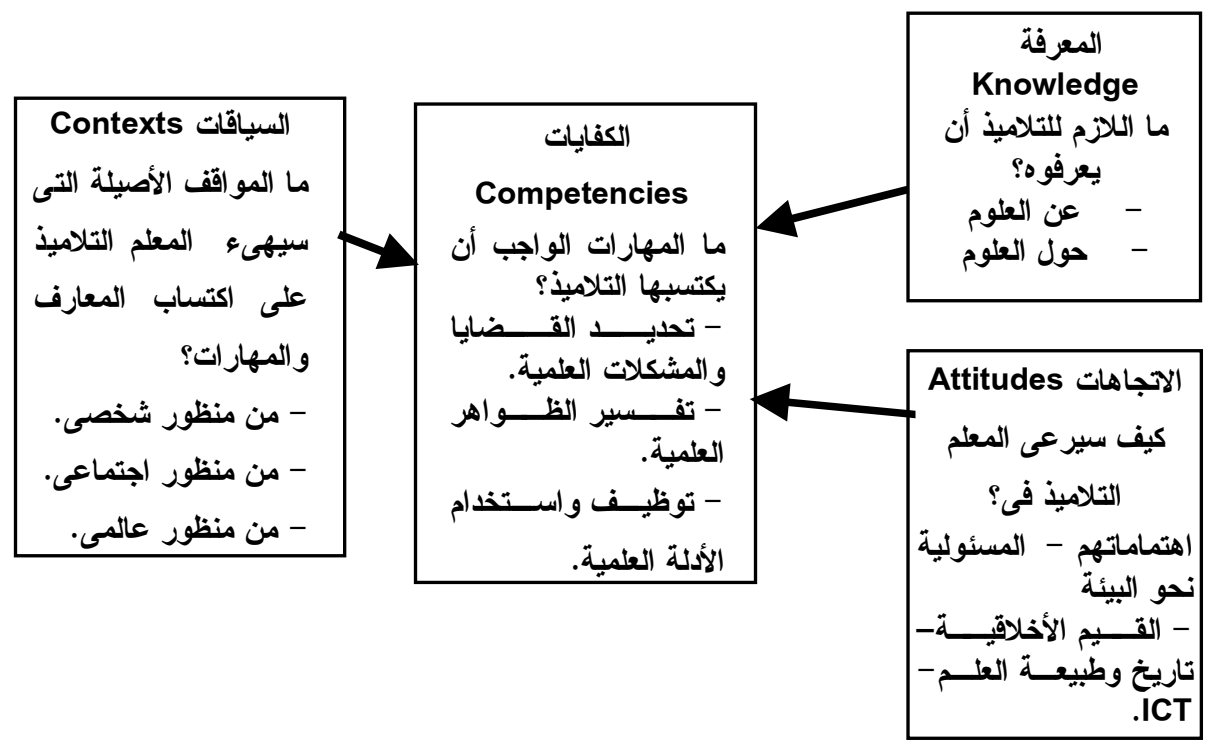

شكل(1) جو اتب الثقافة العلمية من منظور مشروع PISA

V- المراكز الدولية المشرفة على إعداد مشروع PISA دولياً:

تعتبر منظمة التعاون والتتمية الاقتصادية (OECD) الممول الرئيسى

للمشروعهو الذى يشرف عليها"|لبنك الدولى"، بالإضافة إلى عدة مر اكز ومعاهد

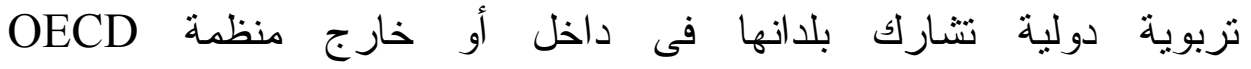

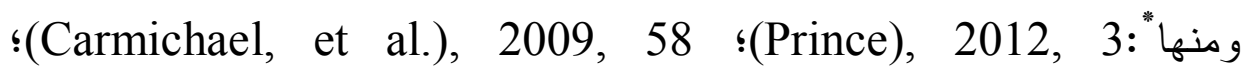
(Lemke, et al.), 2005, 4

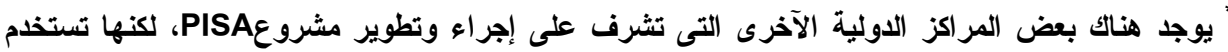

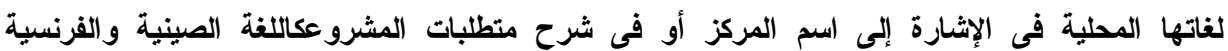

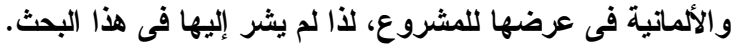


ا - معهد تعليم العلوم و الرياضيات بألمانيا. Germany Institute for

Science Education and Mathematics r- المعهد الألمانى للتنّليم و البحث الدولى. (DIPF) r- وحدة تحليل النظم و الممارسات التعليمية ببلجيكا. (ASPE) عـ المعرد الوطنى الهولندى للقياس التزبوى. Netherlands National Instituted for Educational Measurement ๑ـ المجلس الأستر الى للبحوثالتربوية. Eustralian Council for (ACER) Educational Research ILS وز ارة التربية و التعليم وتطوير المعلمين و المدارس بالنرويج

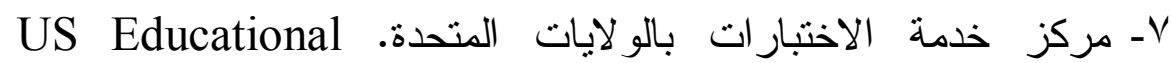
Testing Services A- National Nippon " " المعرة الوطنى لبحثالسياسةالتعليمية باليابان. (NIER) Institute for Educational Policy Research 9- المركز الأمريكى للتحليل الإحصائى. National Center for Education Statistics

A- أهمية المشاركة الدولية فى مشروع PISA:

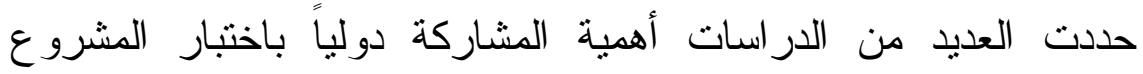

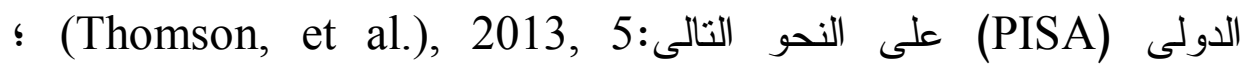
(Carmichael, et al.), ؛(Stacey), 2010, 5؛(OECD), 2013a, 98 ؛OECD) , 2007b , 9 (Bortoli,.and Thomon), 2007, 2 ؛2009, 59

"يستخدم اليابانيون مصطلح Nippon وليس Japan للتبير عن اسم دولتهم "اليابان" باللغة الإجليزية. 
(Tucker, 2000, ؛ ‘(Tout), 2002, 4 ؛(OECD), 2003a, 12

$$
\text { (11 اويمكن توضيحها على النحو التالى: }
$$

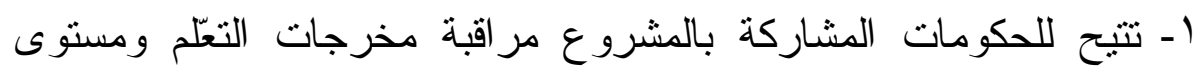

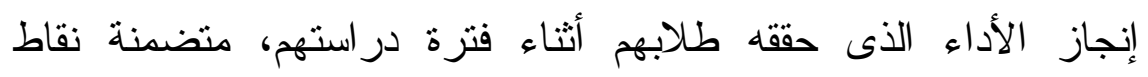

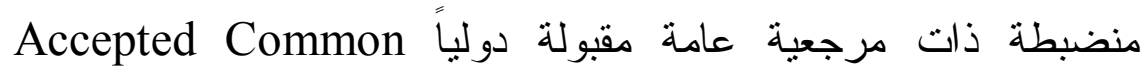
Framework بالإضافة إلى المهام و الأداءات التى اجتازوها حتى دئس ينسم الحكم بالصدق و الموضو عية. r- تجاوز الحدود الجغر افية و إثراء نظم التعَليم لدول العالم الثانى و الدول

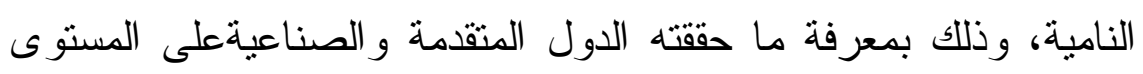
التعليمى. r- مقارنة فلسفة وجوهر تدريس المناهج الدراسية التى يجرى فيها الاختبار من معرفة علميةوكفايات أساسية و اتجاهات علميةتللبلدان المختلفة.

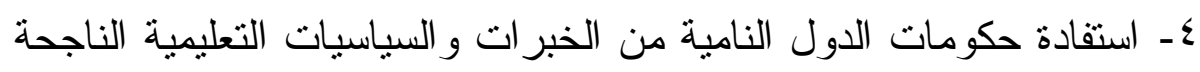
التى حققتها الدول المنقدمة. 0ـ مقارنة نظم و إجر اءات التعلم و التدريس المختلفتبين التلاميذ وتحديد أوجه القوة و الضعف بكل نظام تعليمى.

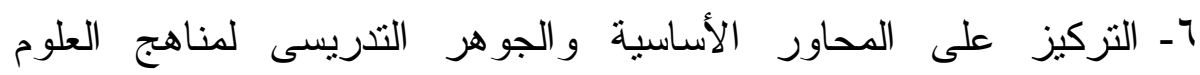
و الرياضيات، و إعداد مناهج مطورة تساعد معلمى هاتين المادنين أثناء

$$
\text { عملية تدريس مناهج داخل المدرسة. }
$$

V- تعزيز تعَّم طلاب مدراس المناطق النائية، وأيضاً تطوير إجراءات دات

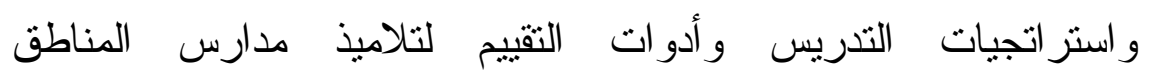

$$
\text { الحضرية. }
$$




\section{9 - أهداف تظوير مناهج العلوم فى ضوء المشروع (PISA):}

يهدف المشروع إلى مساعدة مطورى ومخططى المناهج الدراسية على تضمين جانبى الثقافة العلمية ومهار ات حل المشكلات بمناهج العلوم بمر احل

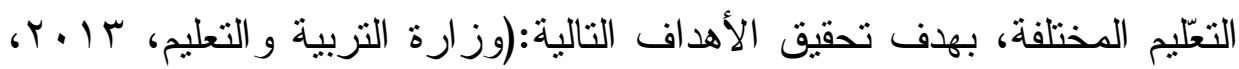
(OECD, ؛(OECD) , 2009b , 128-129 ؛ ؛ (OECD) , 2007b, 9

(Bybee), 2006, 9؛2009c,188-189

1 - مشاركة المتعلم بما تعَلمه و اكتسبه على النحو الجيد فى أثناء تعملمهم داخل المدرسة ويظهر ذلك من خلال صياغتهم للأسئلة العلمية الأساسية وكيفية الإجابة عنها، وشرحهم للظواهر بشكل علمى، وقدرتهم على تحديد القضايا و المشكلات العلمية و اتخاذهم للقر ار ات فى الوقت المناسب.

r- أهمية تضمين مو اقف أصيلة وو اقعية من الحياة المحيطة بالمتعلم تتسم بالصدق و الموضوعية فى معالجتها للمشكلات المحلية أو الدولية، وسيتم هذا خلا اكتساب وتقييم المعرفة العلمية وتوظيف وسائل التكنولوجيا

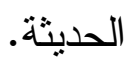

r- المعرفة العلمية لبست فقط مجموعة المعلومات و المبادى و القوانين

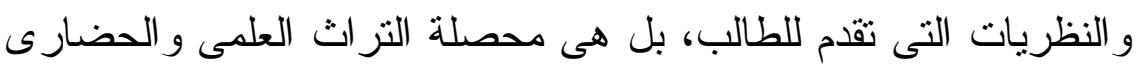
الذى تم توصل إليه من خلال طرحهم للأسئلة العلمية وتفسيرهم للظو اهر

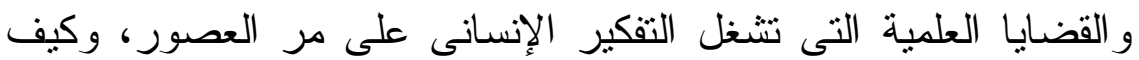
توصل العلماء إلى صياغة مبدأ أو نظرية علمية من خلال الأنساني على الألة

$$
\text { و البر اهين ذات المصداقية و الموضو عية. }
$$


عـ النترّف على خصائص العلم كونه أحد أنثال المعرفة الإنسانية النى من

خلالها أظهرت محاو لات الإنسان Human Endeavour بناء مجتمعه

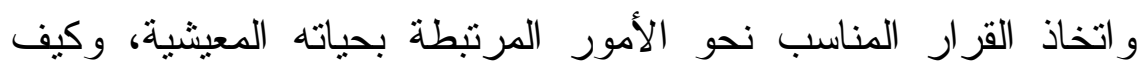
يوظف العلم و التكنولوجيا فى إيجاد حلول للمشكلات أو معالجة مشكلات جديدة.

0- بناء المجتمع المعرفى وتخريج جيل من المتعلمين يشاركون فى بناء

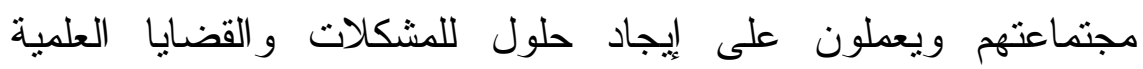
الإقليمية و الدولية التى تتشغل تقكير الرأى العام الدولى وتقدير قيمة العلى

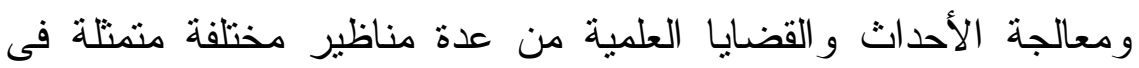

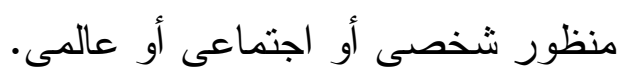

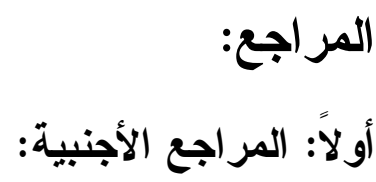

- Anil, Duygu (2011): Investigation of Factors influencing Turkey's PISA 2006 Science Achievement with Structural Equation Modelling, Journal of Educational Science, 11(3), Summer, Pp. 1261-1266.

- Bradshaw, Jenny \& Sturman, Limda \& Vappula, Hanna \& Ager, Rob and Wheater, Rebecca.(2009): "Achievement of 15-Years-Olds in English: PISA 2006 National Report", National Foundation for Educational Research, NFER, Pp.1-13.

- Biagi, Federico and Lio, Massimo (2013): "Measuring ICT Use and Learning Outcomes: Evidence from Recent 
Econometric Studies", Journal of European Education, 48(1), Mars, Pp. 28-42. (Eric: EJ100936).

- Bybee, Rodger W., (1997): "Towards an Understanding of Scientific Literacy", In Grabe, W. and Bolte, C. (Eds.) Scientific Literacy, An International Symposium, IPN.

- Organization for Economic Co-operation and Development (OECD) (2006): Assessing Scientific, Reading, and Mathematical Literacy: A Framework for PISA 2006, Programme for International Student Assessment, Paris, OECD publications.

- Organization for Economic Co-operation and Development (OECD) (2007a): Science Competencies for Tomorrow's World, PISA 2006, Volume(1), Analysis, Programme for International Student Assessment, Paris,OECD publications.

- Organization for Economic Co-operation and Development (OECD) (2007b): PISA 2006: Science Competencies for Tomorrow's World, Executive Summery, Programme for International Student Assessment, Paris,OECD publications.

- Organization for Economic Co-operation and Development (OECD) (2009a): Take the Test, Sample Questions from OECD's PISA Assessments, Programme for International Student Assessment, OECD publications.

- Organization for Economic Co-operation and Development (OECD) (2009b): PISA 2009 Assessment Framework Key Competencies in Reading, Mathematics and Science,Programme for International Student Assessment, OECD publications. 
- Organization for Economic Co-operation and Development (OECD) (2013a):PISA 2012 Assessment and Analytical Framework: Mathematics, Reading, Science, Solving Problems, and Financial Literacy, OECD publications. 